\title{
The Effect of Product Information and Information Privacy Concerns on Acceptance of Facebook Advertising
}

\author{
Hilda Bongazana Mahlangu \\ Department of Marketing, Faculty of Management Sciences, Vaal University of Technology, \\ Private Bag X021, Vanderbijpark 1900, South Africa \\ Email: bongazana.mahlangu@gmail.com
}

\section{Doi:10.5901/mjss.2014.v5n25p198}

\begin{abstract}
Facebook is gaining primacy as a preferred online advertising channel among marketers as it provides consumers with valuable up-to-date product information. As the amount of information about products advertised on Facebook increases, privacy concerns become a major issue. Consumers are concerned about the use and distribution of their personal information without their consent. The purpose of this paper is to investigate the effect of product information and privacy concerns on acceptance of Facebook advertising. The main argument of this paper is that consumers will accept Facebook advertising only when it provides them with valuable up-to-date product information, and when they believe that Facebook keeps their information anonymous and protected. This paper also examines the relationship between attitudes and intention to accept Facebook as an advertising channel. A self-administered questionnaire comprising existing scales was used to collect the required data. A model was developed and tested to a convenience sample of 269 students drawn from a South African public higher education institution located in the Gauteng province. The study hypothesised that product information and privacy impact on acceptance of Facebook advertising. The results indicate that providing valuable product information affects students' intentions to use Facebook as an advertising channel; privacy concerns influences students' attitudes towards Facebook as an advertising channel. Furthermore, the results suggest that privacy concerns affect students' intentions to accept Facebook as an advertising channel; students' attitudes towards the use of Facebook as an advertising channel impacts on their intentions to accept it. The model of the current study appears to be relevant in explaining product information and information privacy concerns as important variables influencing the acceptance of Facebook advertising.
\end{abstract}

Keywords: product information, privacy, Facebook advertising, Facebook acceptance, attitudes

\section{Introduction}

Facebook, with more than 1.3 billion monthly users (Statisticbrain, 2014), is becoming the fastest growing social networking site and a popular advertising channel. As an advertising channel, Facebook is an interactive communication channel and as such offers an added advantage of ensuring that marketers establish real time discussions with their consumers (Butler \& Peppard, 1998) and allows marketers to provide product and/or service information (Hooley, Piercy, \& Nicoulaud, 2012) to its targeted market. Therefore, the main challenge facing marketers is how best to provide consumers with valuable up-to-date product information. Marketers are expected to provide interpretable, easy to understand, concise and consistent information (Lee, Strong, Kahn \& Wang, 2002). Such concise and consistent information allows consumers to evaluate products for purchasing decision-making purposes (James \& Bergh, 1990).

In an attempt to assist marketers, Facebook announced that it would utilise the user's web browsing habits for targeting purposes (eMarketer, 2014). While highlighting the efforts made by Facebook to increase marketers' advertising revenues, such tactics also raise consumers' concerns and hence they require special attention. This initiative can result to vulnerability of consumers' data (Monsuwe', Dellaert \& De Ruyter, 2004) and poses a major threat to their privacy (Malhotra, Kim \& Agarwal, 2004). In interactive communication media like Facebook where consumers are supplied continuously with information (Brackett \& Carr, 2001), it is highly likely that consumers might fear that their personal information may be misused (Vijayasarathy, 2004) which subsequently explain their feelings towards Facebook advertising an outcome leading to their intention to accept Facebook as an advertising channel.

Acceptance of a particular technology refers to an individual's commitment to use the technology (Hsieh \& Wang, 2007) for its intended use. It is therefore, understood that even in the Facebook advertising context, the value of information provided on this platform and the concerns of personal information that consumers provide on this site are predictors of acceptance of Facebook as an advertising channel and subsequently consumers' intentions to use this 
channel to search for product related information.

In general, the capacity of the communication channel to present the required information to consumers will affect their attitudes towards that particular channel (Ducoffe, 1996; Brackett, \& Carr, 2001; Taylor, Lewin, \& Strutton, 2011). Thus, as consumers build positive evaluations about the channel, they will tend to use the same channel in the future and hence form positive attitudes towards the channel. However, there are lack of studies that have investigated the effect of product information, information privacy concerns and the relationship between attitudes and intention to accept Facebook as an advertising channel. The purpose of this study is to show that the value of product information and information privacy concerns influences the acceptance of Facebook advertising.

\section{Research Model and Hypotheses}

Drawing on Ducoffe (1996) and Taylor et al. (2011) studies', consumers form attitudes about advertising information on the Web and advertising on social networking sites. Often, such attitudes are related to how marketers use their private information and how they plan to protect consumers from improper misuse of such information. As such, studies have shown that consumer intention to participate in online transactions is predicted by their acceptance of these media. Figure 1 shows a research mode for this study. Hypotheses will be developed to test relationships among the constructs of the model.

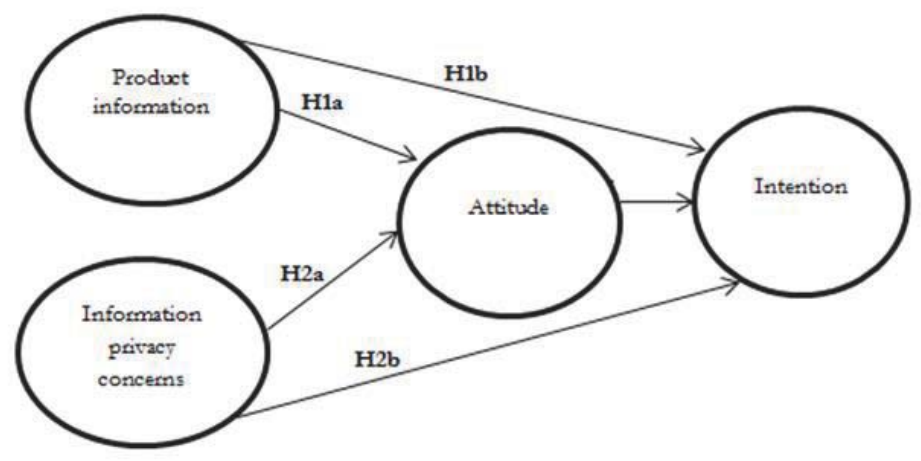

Figure 1: Theoretical model for acceptance of Facebook advertising

\subsection{Product information}

Typically, consumers make purchase decisions based on the amount of available product information (Rodgers \& Thorson, 2000). Clark, Doraszelski \& Draganska (2009) noted that the main source of product information is advertising. Thus, a significant benefit of advertising to the economy is the provision of product information that helps people makes informed purchasing decisions (Petrovici \& Marinov, 2007). As noted by previous studies (Liu \& Arnett, 2000; Lee et al., 2002; Ahn, Ryu \& Han, 2007; Petter, DeLone \& McLean, 2008), advertising is of significant importance in providing consumers with accurate, timely, relevant, complete, and reliable information from which to make final purchase decisions.

In marketing, a communication channel is largely considered an important vehicle for distributing information as well as a way of communicating with customers. As such, the Facebook channel, as a valuable source of advertising information, is expected to deliver information that meets the needs of the users. More recently, Dondolo (2014) noted that when consumers are provided with sufficient product information on Facebook, they value Facebook advertising and thereby forming positive attitudes towards advertising in this particular channel.

In the context of Web advertising, which is a widely studied interactive communication channel, studies indicate that these channels inform consumers of the latest products and provide them with relevant information (Cheng, Blankson, Wang \& Chen, 2009). This clearly support the notion that such interactive channels should provide quality information that is relevant, accurate, concise, complete, understandable, current and usable (Petter et al., 2008) as these aspects are crucial determinants in forming consumer's attitudes towards advertising (Ducoffe, 1996; Brackett \& Carr, 2001; Cheng et al., 2009; Taylor et al., 2011) and intentions to use such a channel. As noted by Tsang, Ho \& Liang (2004), advertising channel that informs consumers of products impacts on overall attitudes towards that particular channel. Therefore, this study hypothesises that: 
$\mathrm{H}_{1 \mathrm{a}}$ : Providing valuable product information can affect students' attitudes towards Facebook as an advertising channel

$\mathrm{H}_{1 \mathrm{~b}}$ : Providing valuable product information can affect students' intentions to use Facebook as an advertising channel

\subsection{Information privacy concerns}

Generally, consumers' privacy concerns have become a major obstacle in online media channel use. This is especially true for online media channels like Facebook, where users share a lot of information. Smith, Milberg, \& Burke (1996) describe information privacy concerns as the extent to which an individual is concerned about organisational practices related to the collection and use of his or her personal information. Campbell (1997) suggests that information privacy concerns involve how users' data are collected, used and controlled. In other words, consumers are often concerned about the inappropriate use of their personal data within these media channels. Vijayasarathy (2004), for example, maintain that consumers worry that the personal information, browsing and shopping history provided online might be misused. Malhotra et al., (2004) correctly posit that the collection of a consumer's personal data by marketers is fair when the consumer is informed of what is to be used and approves it. Taylor et al. (2011), in a study examining attitudes towards social networking sites, found support of the effect of privacy concerns on user's attitudes towards social networking sites. Under these circumstances, information privacy concerns impacts on consumers' acceptance of Facebook advertising. Based on these arguments, this study posits that:

$\mathrm{H}_{2 a}$ : Privacy concerns can negatively affect students' attitudes towards Facebook as an advertising channel

$\mathrm{H}_{2 b}$ : Privacy concerns can negatively affect students' intentions to accept Facebook as an advertising channel

\subsection{Acceptance of Facebook as an advertising channel}

The technology acceptance model (TAM) has been applied to predict user acceptance and behavioural intention to use technology. The theoretical underpinning for TAM is the theory of reasoned action (TRA), which states that a person's behaviour is determined by his or her intention to perform that particular behaviour. According to Ajzen (1991:181), intentions refer to the "motivational factors that influence a behavior; they are indications of how hard people are willing to try, of how much of an effort they are planning to exert, in order to perform the behavior". From the TRA point of view, intentions are linked to attitudes. Attitudes describe the desirability of a particular behaviour to the individual performing the behaviour. Although studies have successfully applied TAM to predict acceptance of a particular technology, few (McCloskey, 2003; Pavlou, 2003; Lian \& Lin, 2008) have applied TAM to predict acceptance of electronic commerce related behaviours and very few studies (Paris, Lee \& Seery, 2010; Lee, Xiong, Chu, 2012) have applied TAM to predict Facebook usage behaviours. For example, Pavlou (2003) suggests that TAM was able to predict consumer on-line behaviour to explain e-commerce. In their study, Lian and Lin (2008) observed that TAM successfully predicted consumer acceptance of online shopping. Therefore, these studies when taken together, confirm the predictive aspects of TAM in relation to online interactive communication channel like Facebook. Therefore, this study proposes that through attitude, the value of product information and information privacy concerns are likely to predict intention to accept FB advertising.

$\mathrm{H}_{3}$ : Students' attitudes towards the use of Facebook as an advertising channel impacts on their intentions to accept it

\subsection{Research methodology}

\subsubsection{Sample and data collection}

This study used a convenience judgement sampling method. Data were collected from 300 students registered at two higher education institutions in the Gauteng province of South Africa.

\subsubsection{Measurement instrument}

Product information, privacy concerns, attitudes and intentions were measured using scales developed from previously validated scales. The items from these scales were adapted to the South African context. Items were measured on a sixpoint scale. 


\subsection{Results}

\subsubsection{Demographic profile of respondents}

Table 1 report on the demographic profile of respondents. Of the questionnaires distributed, 269 were usable. Of the 269 respondents, 45 percent were males and 55 percent were females. Of these respondents, 58 percent accessed Facebook daily, 18 percent a few times a week, 4 percent once a week, 9 percent a few times per month, 11percent once a month. Over 55 percent spend less than an hour on Facebook, 19 percent spend up to two hours per day on Facebook, 11percent spend 2-4 hours on Facebook per day, 8 percent spend more than 8 hours, 3percent spend 4-6 hours, and 3percent spend 6-8 hours on Facebook per day.

Table 1: Demographic profile of respondents

\begin{tabular}{lcc}
\hline & Number & Percent (\%) \\
\hline Gender & 120 & \\
Male & 149 & 45 \\
Female & & \\
How often do you access Facebook? & 31 & 11 \\
Once a month & 24 & 9 \\
A few times per month & 10 & 4 \\
Once a week & 49 & 18 \\
A few times per week & 155 & 58 \\
Daily & & \\
How many hours do you spend on FACEBOOK per day? & 149 & 55 \\
Less than an hour & 51 & 19 \\
Up to 2 hours & 30 & 11 \\
2-4 hours & 09 & 3 \\
4-6 hours & 09 & 3 \\
6-8 hours & 21 & 8 \\
More than 8 hours & & \\
\hline
\end{tabular}

\subsubsection{The measurement model}

The measurement model consisted of four latent variables product information (three indicators), information privacy concerns (three indicators), attitudes (five indicators) and intention (three indicators). Table 2 presents Pearson correlation matrix of the latent constructs. The results demonstrate a significant correlation among intention and its predictors (product information, privacy and intention). This indicates the existence of nomological validity.

Table 2: Correlations matrix among latent variables

\begin{tabular}{lcccc}
\hline & Intention & Product Information & Privacy & Attitude \\
\hline Intention & 0.87 & 0.70 & 0.78 & 0.77 \\
Product information & $0.289^{\star \star}$ & $0.144^{\star}$ & $0.242^{\star \star}$ & \\
Privacy & $0.522^{\star \star}$ & $0.133^{*}$ & & \\
Attitude & $0.279^{\star \star}$ & & & \\
${ }^{*} \mathrm{p}<0.05,{ }^{\star \star} \mathrm{p}<0.01$ (two-tailed) & & & &
\end{tabular}

Convergent validity was assessed by performing confirmatory factor analysis (CFA). Table 3 reports on confirmatory factor analysis, composite reliability, average variance extracted and the square root of average variance extracted. The results showed significant factor loadings ranging from 0.632 to 0.913 . The loadings were above the recommended value of 0.50 (Bagozzi \& Yi, 1998). This demonstrated convergent validity. Reliability was measured by computing composite reliability (CR). The results indicate the existence of composite reliability as all values are above the threshold of 0.70 which indicates internal consistency (Lee, Cheung, \& Chen, 2005). Average variance extracted for all the constructs is above the recommended 0.50 level (Bagozzi \& Yi, 1988). This demonstrates convergent validity. The square root of average variance extracted (values in the diagonal presented in table 2) is above the value of the correlation of the related construct thus demonstrating discriminant validity (Malhotra, 2010). Therefore, the scales used in this study 
display nomological validity, convergent validity, composite reliability, discriminant validity and internal consistency.

Table 3: Standardised factor loadings, CR and AVE

\begin{tabular}{lcccc}
\hline Construct & Item & Factor loadings & CR & AVE \\
\hline \multirow{3}{*}{ Product information } & B1 & 0.681 & & \\
& B2 & 0.758 & 0.73 & 0.50 \\
Privacy & B3 & 0.632 & & \\
& E1 & 0.732 & & \multirow{2}{*}{0.62} \\
Intention & E2 & 0.775 & 0.83 & \\
& E3 & 0.860 & & \\
\multirow{5}{*}{ Attitude } & D11 & 0.871 & 0.90 & 0.75 \\
& D12 & 0.913 & & \\
& D13 & 0.813 & & \\
& B22 & 0.708 & & \\
& B23 & 0.782 & & \\
\hline
\end{tabular}

\subsection{Structural model}

To test the hypothesised relationship among constructs, a structural model was developed. The model was estimated by means of maximum likelihood method. The model provides a good fit with a $x^{2}$ value of $156.549(\mathrm{df}=59, p<0.05)$ with RMSEA $=0.079, \mathrm{CFI}=0.942, \mathrm{TLI}=0.923, \mathrm{GFI}=0.915$, and $\mathrm{NFI}=0.911$. Overall, the fit indices indicate a good fit with values greater than the recommended levels. The ratio of chi-square normalised to degree of freedom ( $x 2 / \mathrm{d})$ was also performed. The results yielded a ratio of 2.65. This ratio indicates that the model has good fit. This is in line with Bentler (1989)'s recommendation that chi-square normalised by degrees of freedom should not exceed a ratio of five. Therefore, the obtained values of chi-square, RMSEA, CFI, TLI, GFI and NFI suggest that the hypothesised model represents an adequate fit to this study's data. The hypotheses of the study were evaluated by examining the path coefficients of the constructs. In reviewing the structural parameter estimates, the paths between intentions and privacy $(p=0.000<0.05)$, intention and product information $(p=0.000<0.05)$, attitudes $(p=0.005<0.05)$ and intentions were significant except the paths between attitude $(p=0.193>0.05)$ and product information. Thus, hypothesis $1 \mathrm{a}$ is not supported by the findings of this study. This finding is unexpected. In his study, Ducoffe (1996) reported a positive and significant relationship between product information value and attitudes towards advertising in an interactive media. Furthermore, the findings of this study did not find support for hypothesis $1 b$. As predicted in this study, information privacy concerns $(p=0.000<0.05)$ had a significant influence on attitude. Therefore, hypothesis $2 \mathrm{a}$ was supported. Hypothesis $2 \mathrm{~b}$ predicted the effects of information privacy concerns on intention. The path estimate was significant $(p=0.000<0.05)$. This infers that hypothesis $2 \mathrm{~b}$ was supported. Consistent with previous research on interactive media that have applied TAM, attitudes $(p=0.005<0.05)$ influenced intentions to accept Facebook as advertising channel. Thus, hypothesis 3 was supported. Table 4 shows the results of the analysis.

Table 4: Summary of results of hypotheses

\begin{tabular}{lc}
\hline Hypothesis & Findings \\
\hline $\mathrm{H}_{1 a}$ : Providing valuable product information can affect students' attitudes towards Facebook as an advertising channel & Not supported \\
$\mathrm{H}_{1 b}$ : Providing valuable product information can affect students' intentions to use Facebook as an advertising channel & Supported \\
$\mathrm{H}_{2 a}$ : Privacy concerns can negatively affect students' attitudes towards Facebook as an advertising channel & Supported \\
$\mathrm{H}_{2 b}$ : Privacy concerns can negatively affect students' intentions to accept Facebook as an advertising channel & Supported \\
$\mathrm{H}_{3}:$ Students' attitudes towards the use of Facebook as an advertising channel impacts on their intentions to accept it & Supported \\
\hline
\end{tabular}

\section{Discussion and Implications}

This study investigated the relation between product information and attitudes, attitudes and intentions as well as information privacy concerns and intentions. There was partial support for the proposed model. Firstly, there was no significant relationship between product information and attitudes. However, an indirect influence of the value of product 
information through attitudes and intentions was observed. For example, providing product information to consumers does not affect their attitudes towards Facebook advertising rather have an indirect effect on their intention to accept Facebook as advertising channel via attitudes. Attitudes and intentions were also significant predictors of acceptance of Facebook as an advertising channel. As expected, this indicates that TAM could be used to successful predict the acceptance of technology like Facebook even within the Facebook advertising context.

A significant relationship between privacy and intentions was obtained. Consistent with findings by Taylor et al.(2011) who reported that privacy concerns were the main concern among social network sites users, the results of this study indicate that information privacy concerns is a strong predictor of intentions to accept Facebook as advertising channel. Although Facebook has announced it will utilise the user's web-browsing habits for targeting purposes, marketers should be extremely careful on how they utilise this information. This study suggests that for consumers to accept Facebook as an advertising channel there is a need to address privacy issues in order to enhance intentions to accept this media. Overall, the findings indicate that information privacy concerns and intentions to accept via attitudes play a major role in determining the acceptance of Facebook advertising.

\section{Limitations and Future Research}

Students were the sample of this study. This raises biasness that may present a question of generalisation of the findings. In future, this study can be replicated in non-student sample group. Secondly, this study only considered few TAM constructs, future research, should include all the TAM constructs when studying this media. Although providing significant results in the effects of these constructs in understanding the acceptance of Facebook as an advertising channel in South Africa, future research should be replicated in other countries to foster cross-cultural comparisons.

\section{Conclusion}

The purpose of this study was to determine the effect of product information and information privacy concerns on acceptance of Facebook advertising. Constructs from TAM, were used as theoretical base to test the proposed model. The findings confirmed the role of attitudes on intentions and privacy on intention to accept Facebook as advertising channel. Although Ducoffe (1996) reported a positive and significant relationship between information value and attitudes towards advertising, the findings of this study report that the path between product information and attitudes towards advertising was non-significant.

\section{References}

Ajzen, I. (1991). The theory of planned behavior. Organisational Behaviour and Human Decision Processes, 50(2): 179-211.

Ahn, T., Ryu, S. \& Han, I. (2007). The impact of web quality and playfulness on user acceptance of online retailing. Information \& Management, 44(3): 263-275.

Bagozzi, R.R. \& Yi, Y. 1998. On the evaluation of structural equation models. Journal of the Academy of Marketing Science, 16(1):74-94.

Brackett, L. K., \& Carr, B. N. (2001). Cyberspace advertising vs. other media: consumer vs. mature student attitudes. Journal of Advertising Research, 41(5):23-32.

Butler, P. \& Peppard, J. 1998. Consumer purchasing on the internet: processes and prospects. European Management Journal, 16(5):600-610.

Clark, C. R., Doraszelski, U., \& Draganska, M. (2009). The effect of advertising on brand awareness and perceived quality: an empirical investigation using panel data. QME, 7(2): 207-236.

Cheng, J.M., Blankson, C., Wang, E.S. \& Chen, L.S. 2009. Consumer attitudes and interactive digital advertising. International Journal of Advertising, 28(3): 501-525.

Dondolo, H.B. (2014). Modelling the factors that influence Generation Y students' attitudes towards advertising in the Facebook environment. Unpublished PhD thesis, North-West University, South Africa.

Ducoffe, R. H. (1996). Advertising value and advertising on the web. Journal of Advertising Research, 36: 21-36.

eMarketer. 2014. Facebook's New Focus Changes the Game for Brand Advertisers. /[Online] Available: http://www.emarketer.com/ Article/Facebooks-New-Focus-Changes-Game-Brand-Advertisers/1010944\#sthash.hkno7hZE.dpuf Date of access: 18 July 2014.

Hooley, G., Piercy, N. \& Nicoulaud, B. 2012. Marketing strategy and competitive positioning. 4th ed. Essex: Pearson Education.

Hsieh, J. P. A., \& Wang, W. (2007). Explaining employees' extended use of complex information systems. European Journal of Information Systems,16(3): 216-227.

James, E. L., \& Bergh, B. G. V. (1990). An information content comparison of magazine ads across a response continuum from direct response to institutional advertising. Journal of Advertising, 23-29.

Lee, Y. W., Strong, D. M., Kahn, B. K., \& Wang, R. Y. (2002). AIMQ: a methodology for information quality assessment. Information \& 
Management, 40(2): 133-146.

Lee, W., Xiong, L., \& Hu, C. (2012). The effect of Facebook users' arousal and valence on intention to go to the festival: Applying an extension of the technology acceptance model. International Journal of Hospitality Management, 31(3): 819-827.

Lian, J. W., \& Lin, T. M. (2008). Effects of consumer characteristics on their acceptance of online shopping: comparisons among different product types. Computers in Human Behavior, 24(1): 48-65.

Liu, C., \& Arnett, K. P. (2000). Exploring the factors associated with Web site success in the context of electronic commerce. Information \& Management, 38(1): 23-33.

Malhotra, N. K., Kim, S. S., \& Agarwal, J. (2004). Internet users' information privacy concerns (IUIPC): the construct, the scale, and a causal model. Information Systems Research, 15(4): 336-355.

Malhotra, N.K. 2010. Marketing research: an applied orientation. 6th ed. Upper Saddle River, N.J.: Pearson/Prentice Hall.

McCloskey, D. (2003). Evaluating electronic commerce acceptance with the technology acceptance model. Information Technology and Organisations: Trends, Issues, Challenges and Solutions, 1:413.

Monsuwé, T. P., Dellaert, B. G., \& De Ruyter, K. (2004). What drives consumers to shop online? A literature review. International Journal of Service Industry Management, 15(1): 102-121.

Paris, C. M., Lee, W., \& Seery, P. (2010). The role of social media in promoting special events: acceptance of Facebook 'events'. Information and Communication Technologies in tourism, 14:531-541.

Pavlou, P. A. (2003). Consumer acceptance of electronic commerce: integrating trust and risk with the technology acceptance model. International Journal of Electronic Commerce, 7(3): 101-134.

Petter, S., DeLone, W., \& McLean, E. (2008). Measuring information systems success: models, dimensions, measures, and interrelationships. European Journal of Information Systems, 17(3): 236-263.

Petrovici, D., \& Marinov, M. (2007). Determinants and antecedents of general attitudes towards advertising: a study of two EU accession countries. European Journal of Marketing, 41(3/4): 307-326.

Rodgers, S., \& Thorson, E. (2000). The interactive advertising model: How users perceive and process online ads. Journal of Interactive Advertising, 1(1): 41-60.

Smith, H. J., Milberg, S. J., \& Burke, S. J. (1996). Information privacy: measuring individuals' concerns about organizational practices. MIS Quarterly, 167-196.

Statisticbrain. 2014. Facebook statistics. [Online] Available: http://www.statisticbrain.com/facebook-statistics/ Date of access: 18 July 2014.

Taylor, D. G., Lewin, J. E., \& Strutton, D. (2011). Friends, fans, and followers: Do ads work on social networks? Business Faculty Publications.

Tsang, M.M., Ho, S. \& Liang, T. 2004. Consumer attitudes toward mobile advertising: an empirical study. International Journal of Electronic Commerce, 8(3):65-78.

Vijayasarathy, L. R. (2004). Predicting consumer intentions to use on-line shopping: the case for an augmented technology acceptance model. Information \& Management, 41(6): 747-762. 